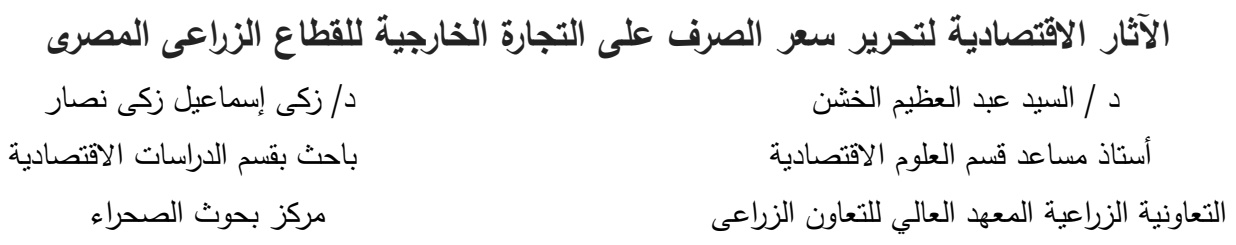

Corresponding Author: elkhishinss@gmail.com

مقدمة:

مما لا شك فيه أن الزراعة في مصر هي الدعامة الأساسية للبنيان الاقتصادي والاجتماعي لم تسهم به من نصيب كبير في عملية التتمية الاقتصادية

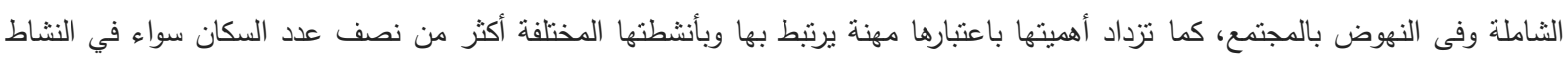

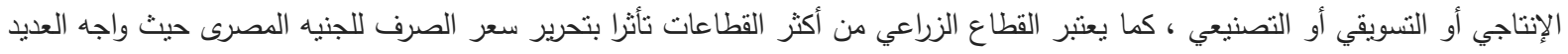

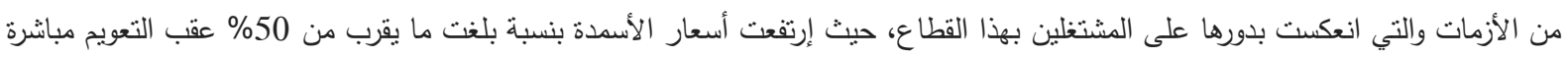

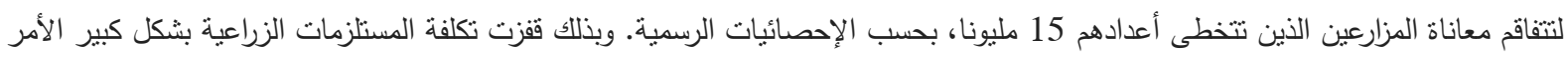
الذي أدى إلى مزيد من الأعباء على المزارعين ولا سيما في ظل ارتفاع أسعار الوقان التود والنقل.

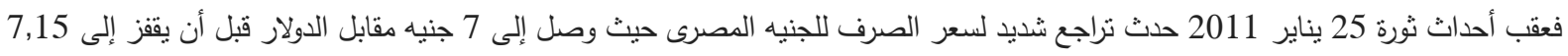

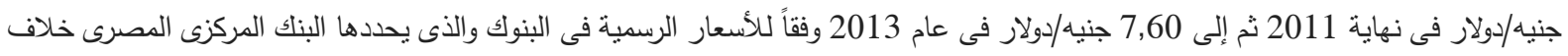

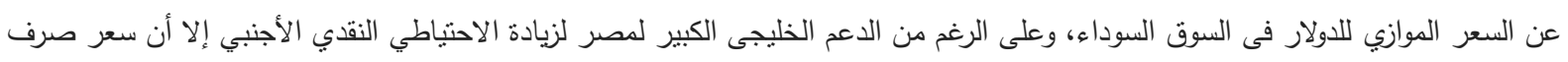

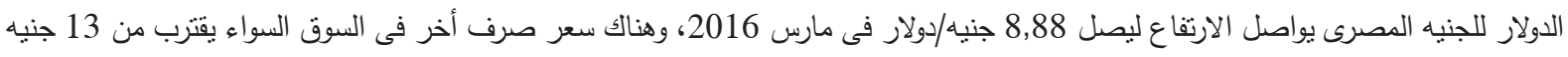

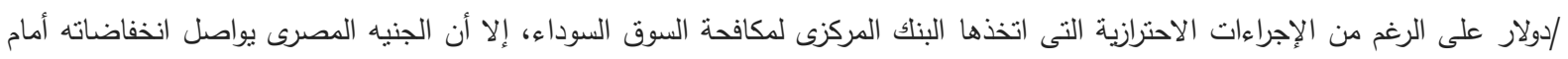

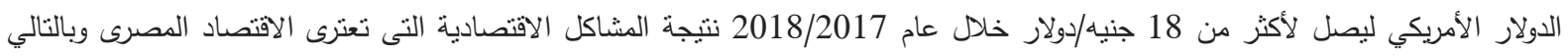

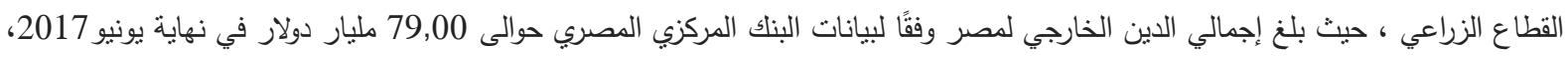

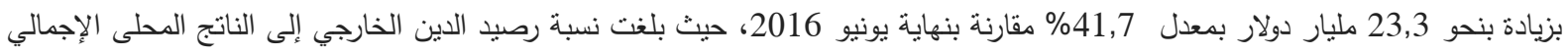

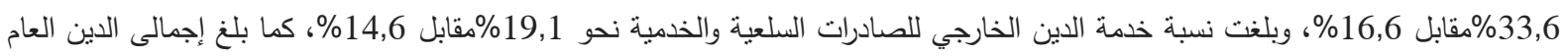

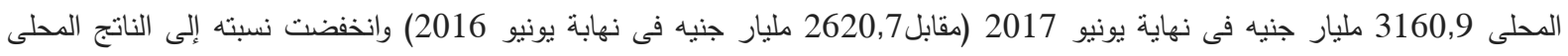

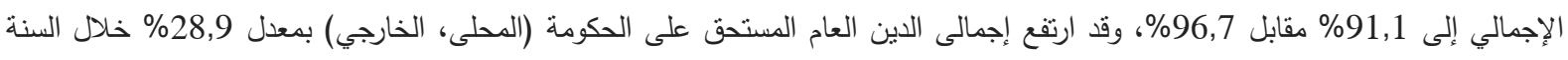

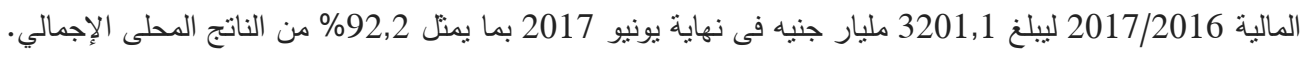

مشكلة البحث: تتحصر المشكلة الأساسية للبحث في الخلل في الميزان التجارى المصرى بثكل عام والميزان الزراعى بثكل خاص وتنزايد حده الفجوة بين الواردات

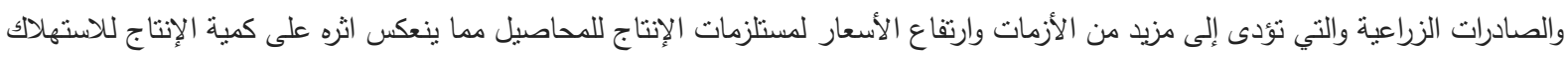

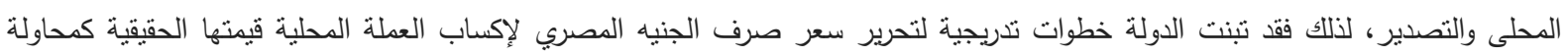

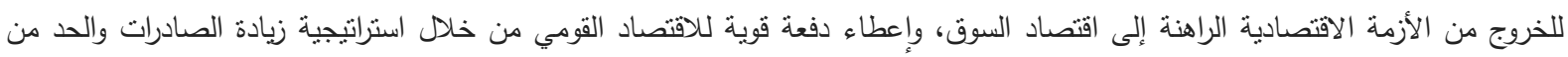

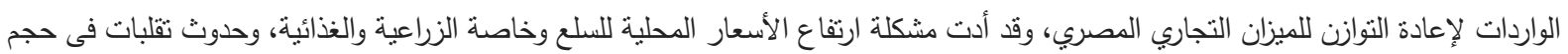

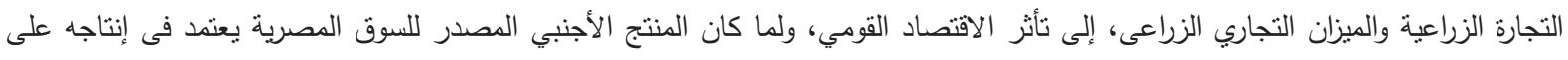

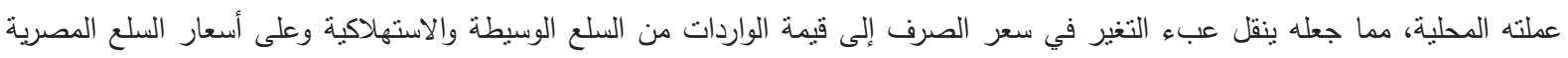

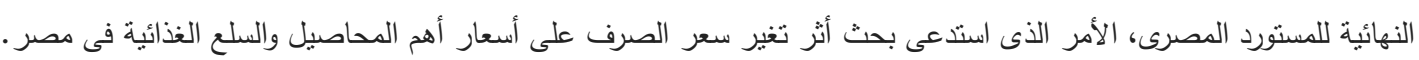

الهذف من البحث:

يهذف البحث بصفة عامة إلى قياس أثر تغير سعر الصرف على الصادرات والواردات الزراعية فى مصر وذلك من خلال تحقيق الأهداف

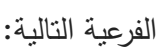
(1) دراسة نطور سعر الصرف خلال الفترتين من (2003-2010) إلى (2011-2018) . 
(2) دراسة تطور إجمالى الصادرات والواردات الكلية خلال الفترتين من(2003-2010) إلى (2011-2018). (3) دراسة نطور الفجوة فى الميزان التجارى خلال الفترتين من (2003-2010) إلى (2011-2018).

(4) دراسة تطور الفجوة فى الميزان الزراعى خلال الفترتين من (2003-2010) إلى (2011-2018)

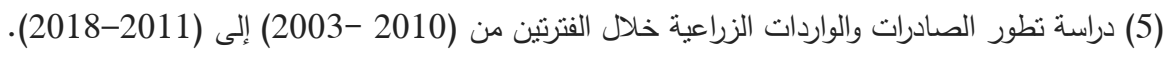

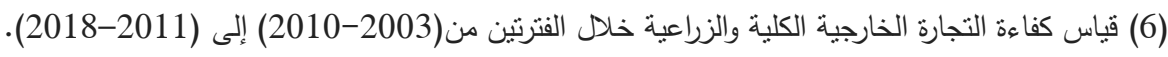
(7) قياس أثر تغير سعر الصرف على التجارة الخارجية الزراعية خلال الفترتين من (2003-2010) إلى (2011-2018).

الطريقة البحثية:

اعتمدت الدراسة على استخدام أدوات التحليل الإحصائي والاقتصاد القياسي حيث تم استخدام إختبار الارتباط بين المتغيرات Cross correlation أثر التمربر Pass - Through Effect، اختبار سبيبة جرانجر Granger Causality وهو إختبار إحصائي يستخدم للتأكد من (وجود علاقة سبيية تبادلية أياكتشاف المتغيرات الداخلية الآنية، أو إختبار العلاقة الزائفة Spurious أي لا يوجد علاقة سبيية، أو إختبار وجود

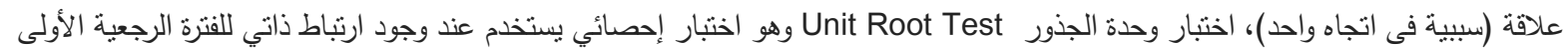

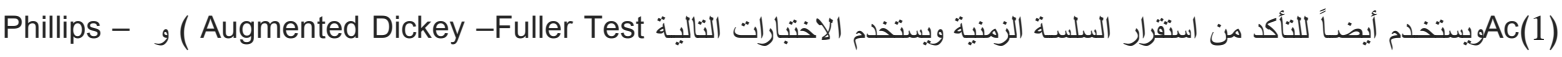
Akaike Information Criterion (A.I.C) ، (Schwarz Bayesian Criterion (S.B.C) اختبارات طول المبطئات ومنه : النهار Perron Test )

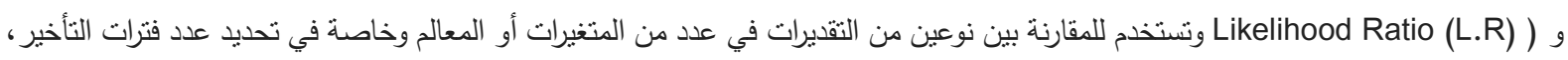

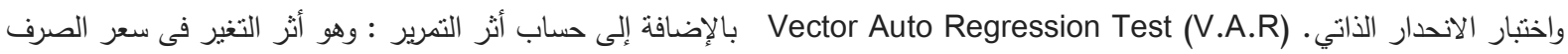

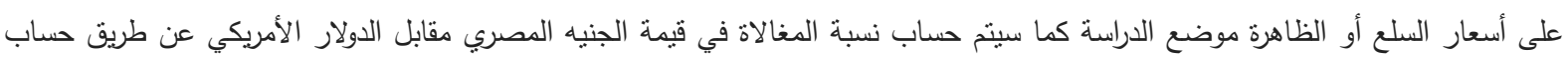
سعر الصرف الحققي للجنيه مقابل الدولار باستخدام الرقم القياسي لأسعار المستهكين في مصر والرقم القياسي لأسعار المستهلكين في الولايات المتحدة بسنة أساس = 2010.

مصادر البيانات: وقد اعتمد البحث على البيانات المنشورة وغير المنشورة بالجهاز المركزي للتعبئة العامة والإحصاء(capmas)، بيانات وزارة الاستثمار ، نشرات البنك المركزى المصرى، نشرات الإدارة المركزبة للاقتصاد الزراعى، مركز دعم واتخاذ القرار بمجلس الوزراء، المنظمة العربية للتتمية الزراعية.

أولاً: تأثير سعر الصرف على الميزان التجاري والزراعي فى مصر خلال الفترة (2003 - 2018): يبين الجدول رقم (1) تطور سعر الصرف وقيمة الصادرات والواردات الكلية والميزان التجاري لمصر بالمليار دولار ، حيث أن سعر

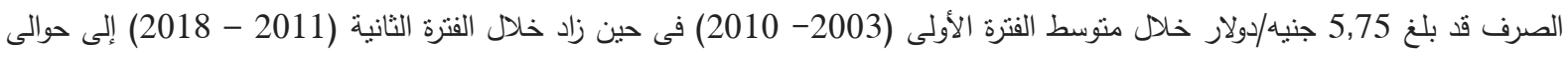
9,94 جنيه/دولار وقد بلغ معدل التغير بين فترتي ما قبل الثورة وبعد الثثرة حولى 72,87\% مما يعكس انخفاض قيمة الجنيه المصرى أمام سعر صرف الدولار بعد الثورة، كما تبين زيادة سعر صرف الدولار مقابل الجنيه من حوالى 10,2 جنيه/دولار عام 2016 إلى حوالى 17,81 جنيه دولار

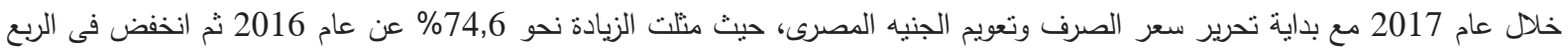
الثالث من عام 2018 إلى حوالى 17,78 جنيه/دولار بنسبة انخفاض تبلغ نحو كما توضح بيانات الجدول رقم (1) أيضا انخفاض إجمالي قيمة الصادرات السلعية الكلية المصرية إلى حوالى 21,340 مليار دولار عام 2015، إلا أنه مع بداية تحرير سعر الصرف تبين زيادة إجمالى قيمة الصادرات السلعية مرة أخرى لتبلغ نحو

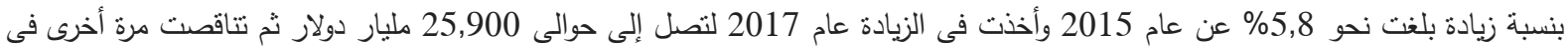

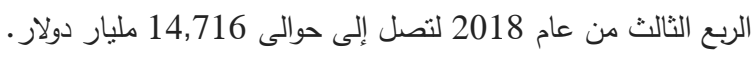
كما تبين أن إجمالى قيمة الصادرات السلعية الكلية المصرية قد أخذت اتجاها عاماً منزايداً بلغ حوالى 0,341 مليار دولار بمثل نحو 1,7 \% من المتوسط البالغ حوالى 20,637 مليار دولار، حيث بلغت حوالى 17,920 مليار دولار خلال متوسط الفترة ما قيل الثورة (2003 -

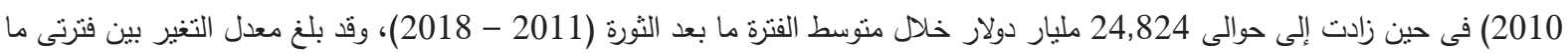

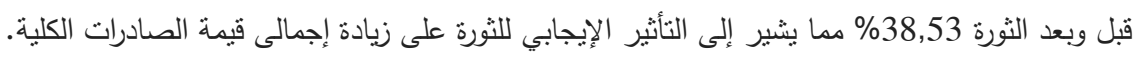
وقد تبين أيضاً من جدول رقم (1) أن إجمالي قيمة الواردات الكلية قد اتخذت اتجاها عاماً متزايداً بلغ حوالى نحو 0,33\% من المتوسط البالغ حوالى 48,081 مليار دولار ، حيث انخفضت مع بداية تحرير سعر الصرف لتبلغ حوالى 69,440 مليار دولار 
عام 2016، تمثل نحو 6,6\% من عام 2015، حيث تبين أن إجمالى قيمة الواردات السلعية المصرية الكلية قد بلغت حوالى 33,326 مليار دولار خلال متوسط الفترة ما قيل الثثرة (2003 - 2010) فى حين زادت إلى حوالى 65,638 مليار دولار خلال منوسط الفترة ما بعد الثورة (2011 -

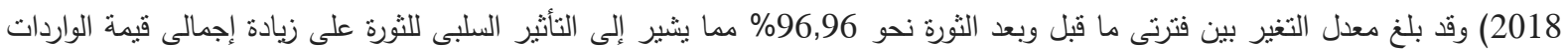

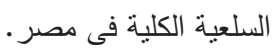

كما يتضح من جدول (1) أن الفجوة فى الميزان التجاري الكلى قد بلغت حوالى 15,407 مليار دولار خلال متوسط فترة ما قبل الثورة (2003 - 2010) فى حين زادت إلى حوالى 40,815 مليار دولار خلال منوسط فترة ما بعد الثثرة (2011 - 2018) وقد بلغ معدل التغير بين الفترتين نجو 264,92\% مما يشبر إلى التأثير السلبى للثثرة على زيادة الفجوة فى الميزان التجارى السلعى الكلى حيث تبين زيادة الفجوة فى الميزان

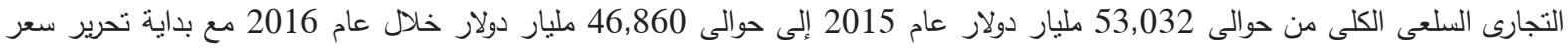
الصرف حيث كانت نسبة الزيادة نحو 204\%من عام 2015 وقد انخفضت الفجوة فى عام 2017 لتصل إلى حوالى 37,460 مليار دولار ثم تتاقصت بعد ذلك فى عام 2018 لتصل إلى حوالى 22,446 بنسبة انخفاض عن عام 2016 بداية تحرير سعر الصرف يقدر بنحو 52,1\% .

جدول (1) تطور سعر الصرف وقيمة الصادرات والواردات الكلية والميزان التجاري لمصر بالمليار دولار خلال الفترة (2003 -2018)

\begin{tabular}{|c|c|c|c|c|c|c|}
\hline للسبة تغطية الصادرات & حجم التجارة & الفجوة فى الميزان & قيمة الو اردات الكلية & قيمة الصنادر ات & سعر الدولار & السنو ات \\
\hline 57 & 104,895 & $4,738-$ & 10,902 & 6,166 & 5,97 & 2003 \\
\hline 60 & 127,394 & $5,159-$ & 12,837 & 7,678 & 6,21 & 2004 \\
\hline 54 & 176,313 & $9,765-$ & 19,808 & 10,043 & 5,79 & 2005 \\
\hline 67 & 197,236 & $6,871-$ & 20,586 & 13,715 & 5,75 & 2006 \\
\hline 60 & 243,842 & $10,874-$ & 27,054 & 16,180 & 5,64 & 2007 \\
\hline 50 & 430,831 & $26,535-$ & 52,793 & 26,258 & 5,45 & 2008 \\
\hline 54 & 384,554 & $20,752-$ & 44,958 & 24,206 & 5,56 & 2009 \\
\hline 50 & 467,562 & 27,890 & 55,249 & 27,359 & 5,66 & 2010 \\
\hline 56,43 & 289,676 & $15,407-$ & 33,326 & 17,920 & 5,75 & متوسط الفترة \\
\hline 48 & 578,878 & 33,865 & 65,415 & 31,550 & 5,97 & 2011 \\
\hline 39 & 633,683 & $45,354-$ & 74,618 & 29,264 & 6,1 & 2012 \\
\hline 43 & 658,666 & $41,206-$ & 66,902 & 25,696 & 6,89 & 2013 \\
\hline 37 & 718,789 & $46,296-$ & 73,838 & 27,542 & 7,09 & 2014 \\
\hline 29 & 732,197 & $53,032-$ & 74,372 & 21,340 & 7,65 & 2015 \\
\hline 33 & 938,608 & $46,860-$ & 69,440 & 22,580 & 10,2 & 2016 \\
\hline 41 & 1589,714 & $37,460-$ & 63,360 & 25,900 & 17,81 & 2017 \\
\hline 40 & 922,398 & $22,446-$ & 37,162 & 14,716 & 17,78 & 2018 \\
\hline 38,75 & 846,617 & $40,815-$ & 65,638 & 24,824 & 9,94 & متوسط الفترة \\
\hline 48 & 556,410 & $23,211-$ & 48,081 & 20,637 & & المتوسط العام \\
\hline 68,67 & 192,26 & $264,92-$ & 96,96 & 28,53 & 72,78 & أثثر الثورة \\
\hline \multirow[t]{2}{*}{145,62} & 34,22 & $22,85-$ & 50,77 & 72,19 & 57,8 & أثثر التعويم \\
\hline & & 17,8 & 6,6 & 5,8 & 74,6 & مقدار الزيادة \\
\hline 39,18 & 62,3 & 83,3 & 20,48 & 6,96 & 14,15 & $\mathrm{~F}$ \\
\hline 72 & 80 & 85 & 57 & 28 & 47 & $\mathrm{R}^{2}$ \\
\hline
\end{tabular}

www.cbe.org.eg- الموقع الإلكتروني للبنك المركزى المصريف:

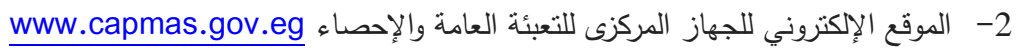

كما يتضح من بيانات جدول (1) أن متوسط حجم التجارة قد بلغ فى فترة ما قبل الثورة حوالى 289,676 مليار دولار وقد زاد فى فترة

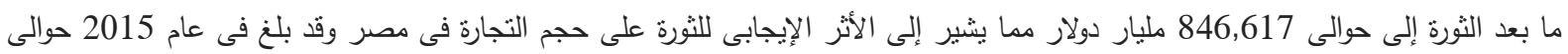

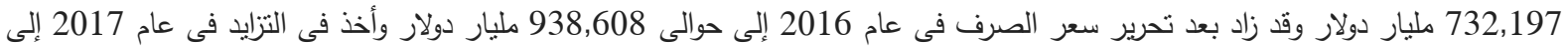

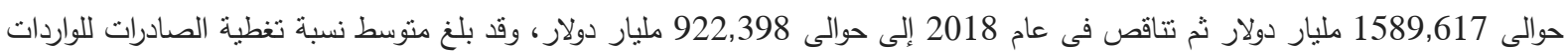
قبل الثورة (2003- 2010) حوالى 56,43 انخفضت إلى حوالى 38,75 كمتوسط للفترة بعد الثورة (2011 - 2018). 
يتضح من بيانات الجدول رقم (2) إجمالى قيمة الصادرات والواردات الزراعية بالمليار دولار خلال الفترة (2003 - 2018)، حيث تبين أن قيمة

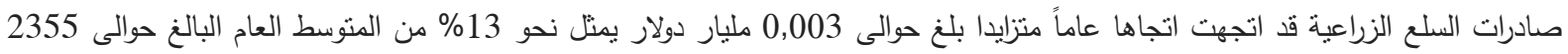

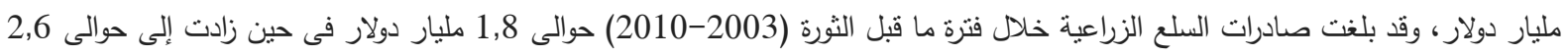

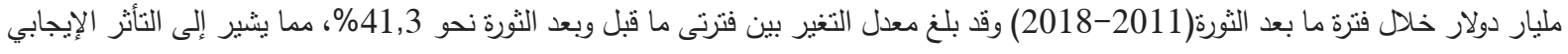

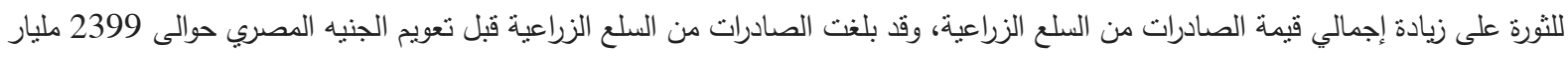
دولار، زادت إلى حوالى 2676 مليار دولار بعد التعويم بنسبة زيادة بلغت نحو 11,5\% وقد ترجع هذه الزيادة الكيادة إلى نحرير سعر الصرف للجنيه

المصري.

جدول (2) تطور إجمالى قيمة الصادرات والواردات الزراعية بالمليار دولار خلال الفنرة (2003 - 2018) ـ

\begin{tabular}{|c|c|c|c|}
\hline الفجوة فى الميزان الزر اعى & الآلواردات الزر اعية & الصنادر ات الزر اعية & 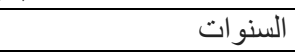 \\
\hline $907-$ & 1684 & 0,777 & 2003 \\
\hline $601-$ & 1706 & 1105 & 2004 \\
\hline $1490-$ & 2408 & 0,918 & 2005 \\
\hline $1414-$ & 2269 & 0,855 & 2006 \\
\hline $2445-$ & 3647 & 1202 & 2007 \\
\hline $2744-$ & 4819 & 2075 & 2008 \\
\hline $1475-$ & 4390 & 2915 & 2009 \\
\hline $202-$ & 2296 & 2093 & 2010 \\
\hline $1409,9-$ & 2902,4 & 1878 & متوسط فترة ما قبل الثورة \\
\hline $5185-$ & 8211 & 3026 & 2011 \\
\hline $6123-$ & 8806 & 2683 & 2012 \\
\hline $2269-$ & 5140 & 2871 & 2013 \\
\hline $1130-$ & 4045 & 2915 & 2014 \\
\hline $824-$ & 3223 & 2399 & 2015 \\
\hline $1164-$ & 3840 & 2676 & 2016 \\
\hline $1511-$ & 4281 & 2770 & 2017 \\
\hline $780-$ & 2663 & 1883 & 2018 \\
\hline $2373,3-$ & 5026,13 & 2652,9 & متوسط فترة ما بعد الثورة \\
\hline 1891,6- & 2964,25 & 2354,85 & المتوسط العام \\
\hline 68,3- & 73,2 & 41,3 & أثر الثثرة \% \\
\hline $41,3-$ & 19,14 & 11,5 & أثر التعويم \% \\
\hline $0,002-$ & 0,001 & 0,003 & مقدار الزيادة \\
\hline 0,018 & 1,642 & 16,77 & $\mathrm{~F}$ \\
\hline $0,07-$ & 0,04 & 51 & $\mathrm{R}^{2}$ \\
\hline
\end{tabular}

www.capmas.gov.eg الموقع الإكتروني للجهاز المركزي للتعبئة العامة والإحصاء

ويتضح أيضاً أن قيمة واردات السلع الزراعية المصرية قد أخذت اتجاها عاماً متزايداً غير معنوي إحصائياً بلغ حوالى 0,001 مليار دولار يمثل

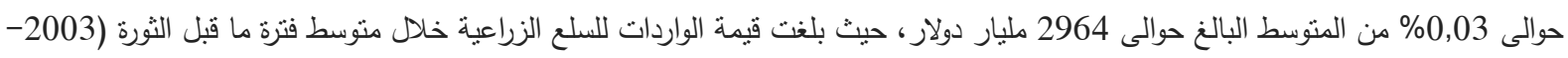

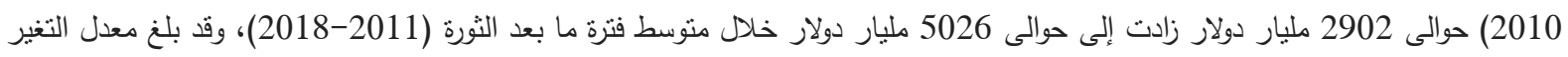

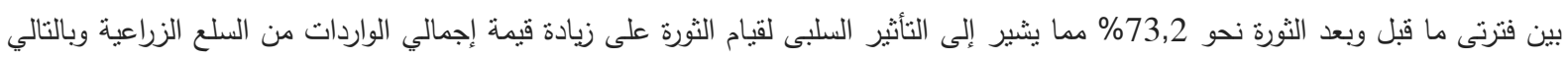

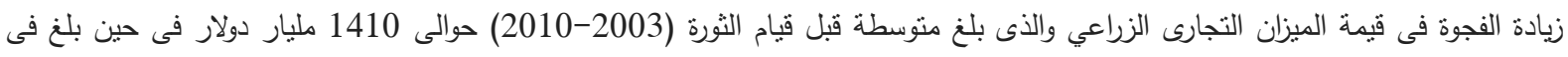

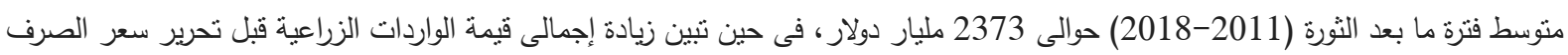

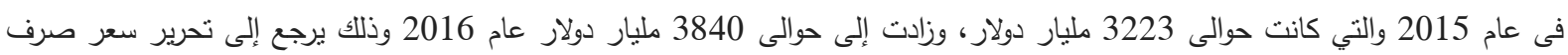

الجنيه المصرى وتمثل نسبة الزياد نحو 19,14\%

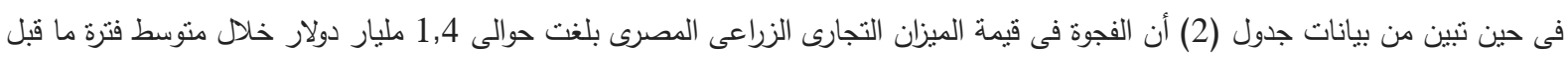

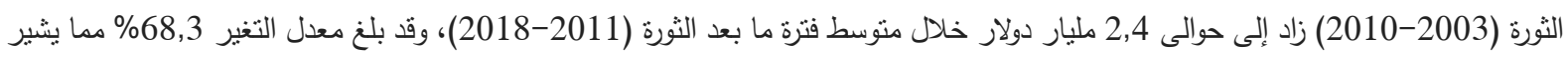

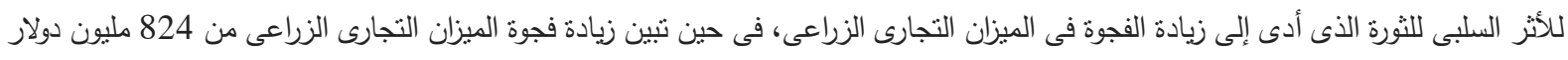

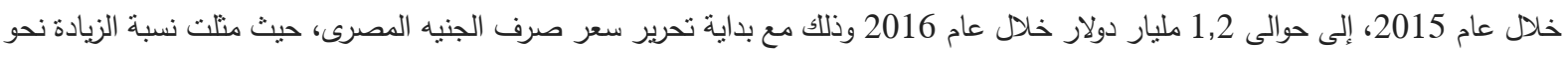

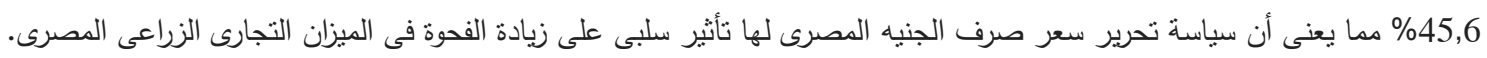


ثالثا: معايير قياس كفاعة التجارة الخارجية الكلية والزراعية المصرية خلال الفترة (2003-2018): باستعراض ودراسة البيانات الواردة بالجدولين رقم (3)،(4) حيث يبينان معايير كفاءة التجارة الخارجية الكلية والتجارة الخارجية الزراعية خلال الفترة (2018-2003) يتضح أن هنالك انخفاض فى قيمة التجارة الخارجية المصرية وخاصة خلال فترة ما قبل ثورة يناير، حيث تبين انخفاض درجة

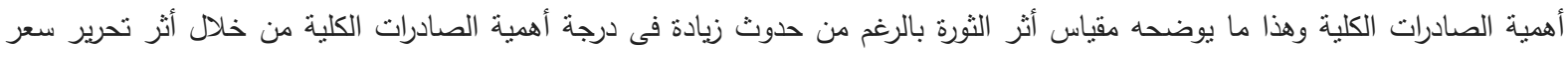

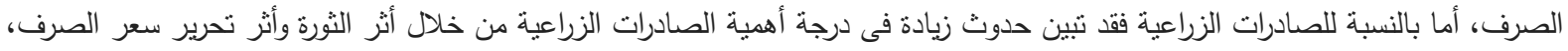
فى حين تبين حدوث انخفاض فى درجة أهمية الواردات الكلية من خلال أثز الثورة وأثر تحرير سعر الصرف أما بالنسبة للواردات الزراعية فقد تنين حدوث زيادة فى درجة أهمية الواردات الزراعية وذلك ما يوضحه أثر الثورة وأثر تحرير سعر الصرف، كما تبين حدوث انخفاض في درجة أهمية التجارة الكلية من خلال مؤشر أثر الثثرة وأثر تحرير سعر الصرفة دردة أما بالنسبة للتجارة الزراعية فقد تبين حدوث زيادة في درجة أهمية التجارة الزراعية

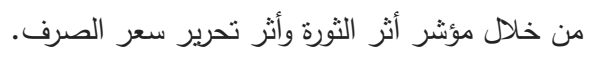

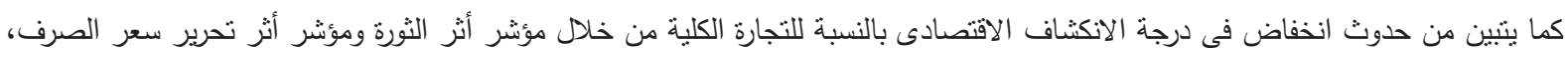

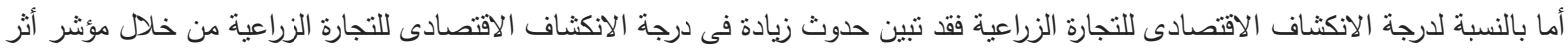

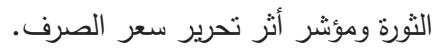
كما يتضح حدوث انخفاض فى معدل تغطية الصادرات الكلية وذلك من خلال نتائج مؤشر أنز الثورة بالرغم من حدوث زيادة فى معدل تغطية الصادرات الكلية من خلال نتائج مؤشر أثر تحرير سعر الصرف، أما بالنسبة للتجار الزراعية فقد تبين حدوث زيادة فى معدل تغطية الصادرات

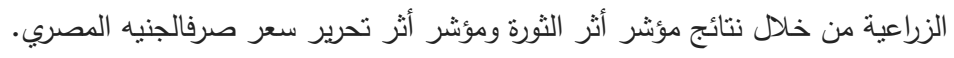
وفى ضوء نتائج الجدولين رقم (3)، (4) يتضح حدوث زيادة فى منتوسط نصيب الفرد من التجارة الخارجية الكلية وذللك من خلال مؤشر أثر الثورة بالرغم من حدوث انخفاض فى متوسط نصيب الفرد من التجارة الخارجية الكلية من خلال مؤشر تحرير سعر صرف الجنيه المصرى، أما بالنسبة للتجارة الزراعية فقد تبين أيضاً حدوث زيادة فى منوسط نصيب الفرد من التجارة الخارجية الزراعية من خلال مؤشر أثر الثورة، وحدوث

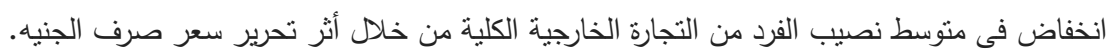

جدول (3) معايير كفاءة التجارة الخارجية الكلية والزراعية خلال الفترة (2003- 2018) .

\begin{tabular}{cccccc}
\hline \multicolumn{2}{c}{ المصnnn} \\
\cline { 1 - 3 }
\end{tabular}


جدول (4) معايير كفاءة التجارة الخارجية الكلية والزراعية خلا الفترة (2003- 2018)

\begin{tabular}{|c|c|c|c|c|c|}
\hline \multicolumn{2}{|c|}{ أثر تحريز سعر الصرف } & \multicolumn{2}{|c|}{ أثُ ثُورة يناير 2011} & \multirow{2}{*}{ الوحدة الوح } & \multirow{2}{*}{ 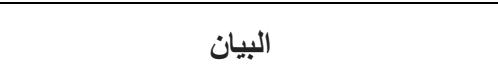 } \\
\hline التجارة الزراعية & التجارة الكلية & التجارة الزراعية & التجارة الكلية & & \\
\hline $7,4-$ & $9,2-$ & 33,0 & $18,4-$ & $\%$ & درجة أهمية التجارة الكلية \\
\hline 9,4 & 3.6 & 49,4 & $38-$ & $\%$ & درجة أهية الصسادر ات \\
\hline $13,6-$ & $12,3-$ & 28,8 & $8,4-$ & $\%$ & درجة أهمية الو اردات \\
\hline $7,4-$ & $9,3-$ & 33,0 & $18,4-$ & $\%$ & درجة الانكثاف الاقتصادى \\
\hline 26,6 & 18,1 & 16,0 & $36,3-$ & $\%$ & درجة التغطية \\
\hline $9,3-$ & $8,1-$ & 155,6 & 48,8 & 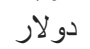 & متوسط نصيب الفرد من التجارة الكلية \\
\hline 10,7 & 4,8 & 170,6 & 17,2 & 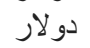 & متوسط نصيب الفرد من الصادر ات \\
\hline $12,6-$ & $11,2-$ & 150,6 & 65,9 & 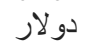 & متوسط نصيب الفرد من الو اردات \\
\hline 1,2 & 1,2 & 84,2 & 84,2 & 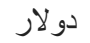 & متوسط نصيب الفرد من صافى الناتج المحلى \\
\hline 3897,3 & 162,3 & $65,7-$ & $34,7-$ & $\%$ & معامل عدم الاستقر ار للتجارة الكلية \\
\hline 62,3 & $3,9-$ & $68,9-$ & 3,7 & $\%$ & معامل عدم الاستقر ار للصـادر ات الكلية \\
\hline 3092,0 & 115,6 & $53,0-$ & 78,4 & $\%$ & معامل عدم الاستقر ار للواردات الكلية \\
\hline 9,2 & 3,1 & 228,2 & 26,9 & $\%$ & معدل النمو للصادرات الكلية \\
\hline 4,2 & 7,9 & 42,5 & 24,8 & $\%$ & معدل النمو للواردات الكلية \\
\hline
\end{tabular}

وفى ضوء نتائج الجدولين (3) ، (4) تبين حدوث زيادة في متوسط نصيب الفرد من الصادرات الكلية من خلال مؤثر أثر الثورة ومؤشر أثر تحرير

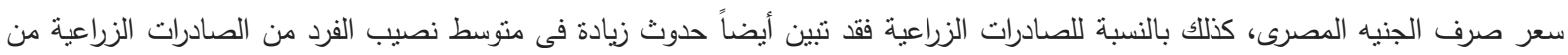
خلال مؤثر أثر الثورة ومؤشر أثر تحرير سعر الصرف، كما تبين زيادة متوسط نصيب الفرد من الواردات الكلية من خلال مؤشر أثر الثورة أما

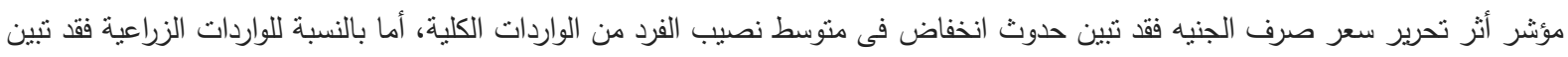

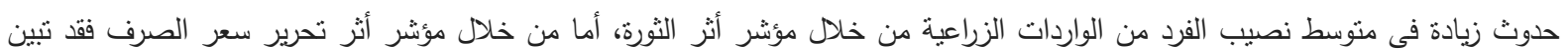

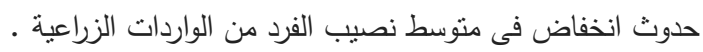

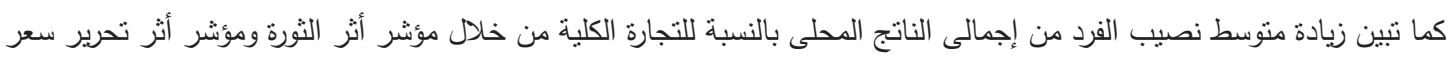

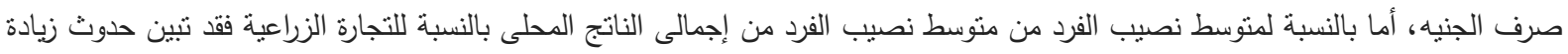

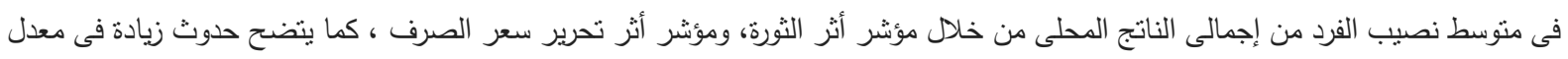

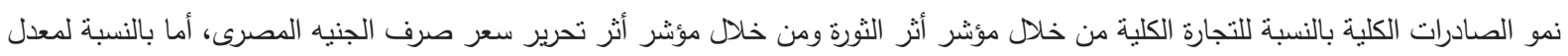

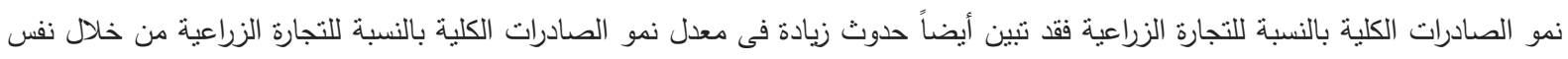
المؤشرين • المبادرات

كما يتضح زيادة معدل عدم الاستقرار للصادرات الكلية بالنسبة للتجارة الكلية من خلال مؤشري أثر الثثرة، وحدوث انخفاض من خلال

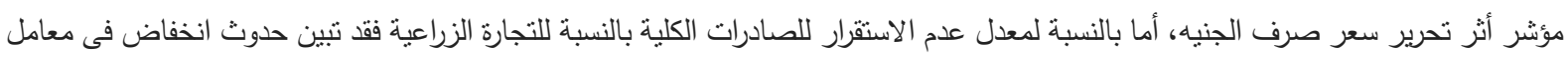

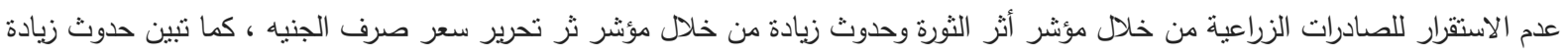

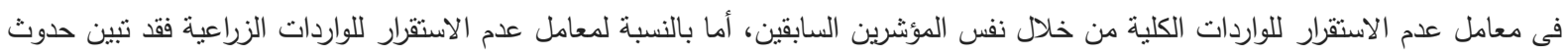

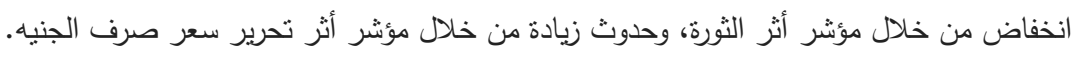

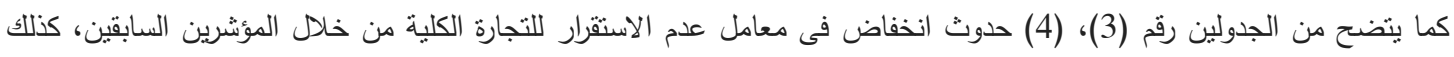

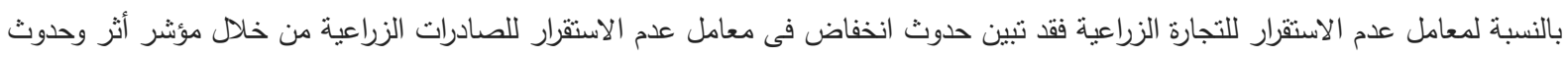

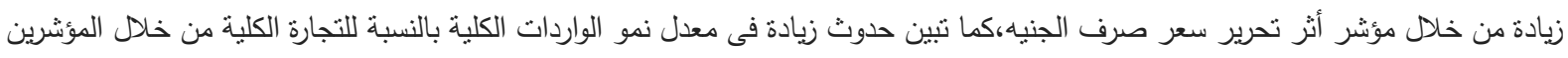

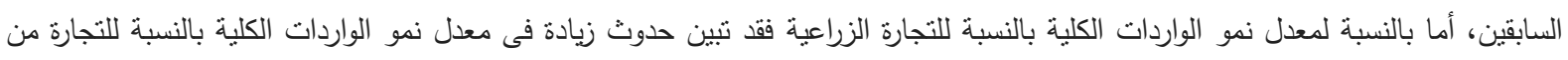

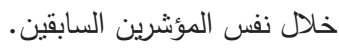

رابعا: التقدير القياسي لنموذج أثر تغير سعر الصرف على الميزان التجارى والميزان الزراعى المصرى خلال الفترة (2003 - 2018):

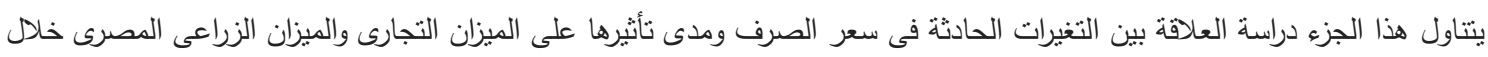

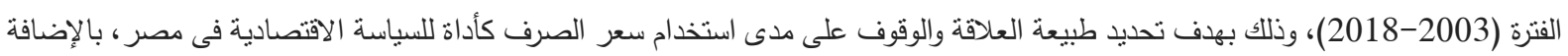


إلى معرفة مدى تطابق حالة الاقتصاد المصرى مع النظرية الاقتصادية والتي تؤكد أن الانخفاض فى سعر الصرف يؤدى إلى تخفيض العجز فى الميزان التجارى.

1- اختبار استقرار السلاسل الزمنية (Augmented Dickey Fuller Test):

يتضح من اختبار Corrologram لجميع متغيرات البحث وتشمل (الميزان التجاري، الميزان الزراعي، سعر الصرف) أنها نعانى من مشكلة التذبذب وعدم الاستقرار عند المستوى الصفري، ولكنها تصبح مستقرة عند الفرق الأول من جذر الوحدة مما بعنى أن السلاسل الزمنية تتحرك معاً

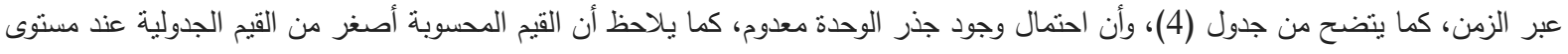
معنوية (0,05) وبالتالي يتم رفض فرض العدم وقبول الفرض البديل، حيث تبين بعد إجراء الفرق الأول استقرار كلاً من سلاسل الميزان التجاري والميزان الزراعي، والصادرات الكلية والواردات الكلية، وسعر صرف وفئ الجنيه مقابل الدولار (شكل 1).

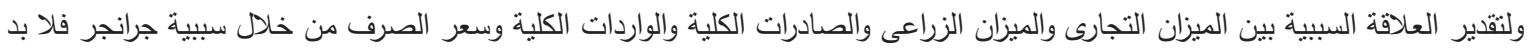
unit root من توافر شروط استقراريه السلاسل الزمنية وأن تكون من نفس الدرجة، ولدراسة استقراريه السلاسل الزمنية فلأبد من إجراء جذر الوحدئ

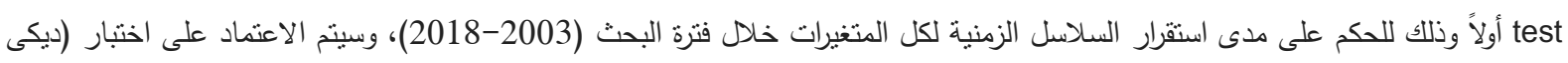

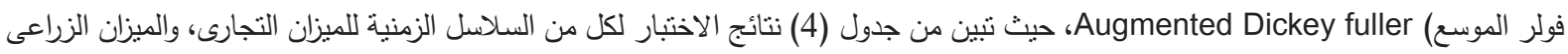
(الصادرات الكلية، الواردات الكلية)، وسعر صرف الجنيه مقابل الدولار . وقد نبين اتفاق هذه النتائج مع النظرية القياسية والتي تفترض أن معظم المتغيرات الاقتصادية الكلية غير ساكنة فى المستوى الصفري، ولكنها تكون ساكنة عند إجراء الفرق الأول على جذر الوحدة، كما نتفق خاصية الاستقرار بعد أخذ الفروق الأولى لكل من رصيد الميزان التجارى والميزان

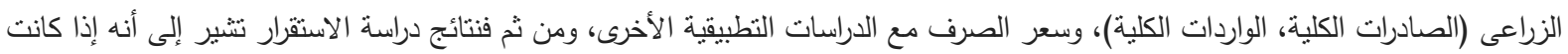
توجد علاقة طويلة الأجل بين المتغيرات الحقيقية الأساسية، وفى ظل التأكد من أن جميع المتغيرات لها نفس درجة التهات التكامل، لذا سيتم إجراء طريقة المربعات الصغرى Ordinary Least Square لبكون وصفاً ملائماً يربط بين قيم المشاهدة لهذه المتغيرات فى الأجل القصير ومسارها التوازني فى الأجل الطويل، إضافة إلى ذلك فأن العلاقة التوازنية تعنى أنه لا يمكن لأى من المتغيرات التحرك باستقلال عن الأخر وهو ما أدى إلى إجراء

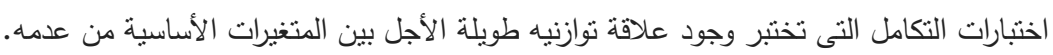

2- اختبار سبيية جراجر Granger Causally Test:

نم إجراء اختبار اتجاه العلاقة السببية بين منغير سعر صرف الجنيه ورصيد الميزان التجارى (الصادرات الكلية، الواردات الكلية) لمعرفة أي منهما يؤثر على الأخر، ومن شروط إجراء اختبار السبيية أن تكون المتغيرات مستقرة من نفس الدرجة وهو شرط تم تحقيقه.

جدول (4) نتائج اختبار (ADF) للنماذج المقدرة خلال الفترة (2003 - 2018)

\begin{tabular}{|c|c|}
\hline $\begin{array}{c}\text { t-statistic } \\
\text { اختبار الوحدة(Unit Root Test) }\end{array}$ & 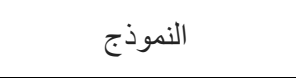 \\
\hline $3,48-*$ & سعر الصرف \\
\hline $2,39-* *$ & الصسادر ات الكلية \\
\hline $2,39-* *$ & الواردات الكلية \\
\hline $2,61-* *$ & الميزان التجارى الكلى \\
\hline $4,44-* *$ & الصنادر ات الزر اعية \\
\hline $3,86-* *$ & الو اردات الزر اعية \\
\hline $4,64-* *$ & الميزان التجارى الزر اعى \\
\hline
\end{tabular}

المصدر : جمعت وحسبت من نتائج تحليل نموذج لباستخدام برنامج (E- Views 9)

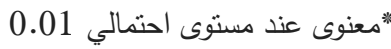

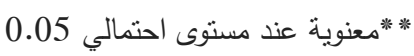

3- 3 نتائج نماذج التجارة الخارجية الكلية والزراعية المقرة: -

أ- - نتائج نموذج الصادرات الكلية المقدرة

تبين من نتائج تقدير نموذج نأثنر سعر الصرف على الصادرات الكلية خلال الفترة (2003 - 2018) أن معامل الارتباط بلغ حوالى 0,93 مما يشير إلى وجود علاقة طردية بين الصادرات الكلية كمتغير مستقل وسعر صرف الجنيه مقابل الدولار كمتغير تابع، كما بلغ معامل التحديد

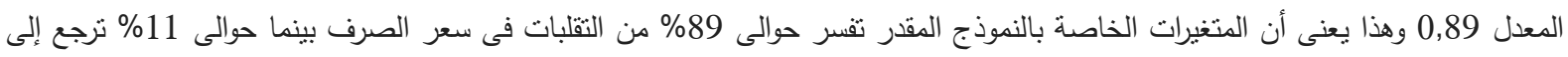
عوامل أخرى لم بيضمنها النموذج. 
$\log (\dot{Y})=4.3634+0.5864 \log \left(x_{1}\right)+0.7381 \mathrm{AR}_{(1)}$
$(3,94) *$
$(1,92)^{* *}$
$(14,37)^{*}$

$\mathrm{R}^{2}=0.892$

$\mathrm{F}=76.3$

0.050 .0100 * * معنوية عند مستوى احتمالية عند مستوى احتمالية

شكل رقم (1) الارتباطات الرجعية والارتباطات الجزئية لنماذج التجارة الخارجية

Dato: 10/18/18 Time: 01:47

Sample: 20032018

Included observations: 15
Date: 10/18/18 Time: 01:45

Sample: 20032018

Included observations: 15

\begin{tabular}{|c|c|c|c|c|c|c|c|c|c|c|c|c|c|c|c|c|c|}
\hline \multicolumn{2}{|c|}{ Autocorrelation } & \multicolumn{2}{|c|}{ Partial Correlation } & \multicolumn{2}{|r|}{$A C$} & PAC & Q-Stat & Prob & \multicolumn{2}{|c|}{ Autocorrelation } & \multicolumn{3}{|c|}{ Partial Correlation } & $A C$ & PAC & Q-Stat & Prob \\
\hline$b$ & 1 & $b$ & 1 & 1 & 0.042 & 0.042 & 0.0314 & 0.859 & 1 & 1 & 1 & 다 & 1 & $1-0.109$ & -0.109 & 0.2180 & 0.641 \\
\hline 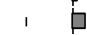 & । & $\square$ & 1 & 2 & 0.143 & 0.142 & 0.4353 & 0.804 & 1 & । & । & & I & 20.063 & 0.052 & 0.2961 & 0.862 \\
\hline $\mathrm{I}$ & 1 & $\square$ & $\mathrm{I}$ & 3 & 0.165 & 0.157 & 1.0135 & 0.798 & 1 & & 1 & & ] & 30.428 & 0.446 & 4.1845 & 0.242 \\
\hline 0 & 1 & 0 & 1 & 4 & 0.088 & 0.063 & 1.1938 & 0.879 & 1 & , & 1 & & 1 & $4-0.132$ & -0.045 & 4.5894 & 0.332 \\
\hline$i$ & 1 & 0 & 1 & 5 & -0.036 & -0.086 & 1.2263 & 0.942 & 1 & 1 & 1 & 다 & 1 & $5-0.025$ & -0.147 & 4.6059 & 0.466 \\
\hline d & 1 & ㅁ & I & 6 & -0.105 & -0.159 & 1.5380 & 0.957 & 1 & 1 & 1 & & 1 & $\begin{array}{ll}6 & 0.191\end{array}$ & 0.003 & 5.6363 & 0.465 \\
\hline d & 1 & 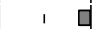 & $\mathrm{I}$ & 7 & -0.100 & -0.117 & 1.8588 & 0.967 & $\square$ & 1 & 1 & $\square$ & 1 & $\begin{array}{ll}7 & -0.322\end{array}$ & -0.260 & 8.9394 & 0.257 \\
\hline , 口 & 1 & 미 & $\mathrm{I}$ & 8 & -0.199 & -0.166 & 3.3048 & 0.914 & & 1 & 1 & $\square$ & 1 & $8-0.142$ & -0.232 & 9.6746 & 0.289 \\
\hline 1 & 1 & $\square$ & 1 & 9 & 0.039 & 0.132 & 3.3686 & 0.948 & & I & 1 & & I & 90.101 & 0.043 & 10.107 & 0.342 \\
\hline $1 \square$ & 1 & $1 \square$ & 1 & 10 & -0.367 & -0.292 & 10.246 & 0.419 & $\square$ & 1 & 1 & & 1 & $10-0.327$ & -0.043 & 15.549 & 0.113 \\
\hline 10 & 1 & 10 & 1 & 11 & -0.083 & -0.035 & 10.683 & 0.470 & 10 & 1 & 1 & & 1 & $11-0.054$ & 0.018 & 15.732 & 0.151 \\
\hline 1 & 1 & 0 & 1 & 12 & -0.008 & 0.056 & 10.688 & 0.556 & 1 & 1 & 1 & 미 & 1 & $12-0.087$ & -0.195 & 16.382 & 0.174 \\
\hline d & 1 & i & I & 13 & -0.076 & -0.010 & 11.434 & 0.57 & I & I & 1 & & 1 & $13-0.052$ & 0.166 & 732 & 0.212 \\
\hline 1 & 1 & 0 & 1 & 14 & -0.003 & 0.040 & 11.436 & 0.651 & 1 & 1 & 1 & & 1 & $14-0.031$ & -0.015 & 16.982 & 0.257 \\
\hline
\end{tabular}

نموذج الواردات الكلية

Dato: 10/18/18 Time: 01:49 Sample: 20032018 Included observations: 15
Dato: 10/18/18 Time: 01:47

Sample: 20032018

Included observations: 15

\begin{tabular}{|c|c|c|c|c|c|c|c|c|c|c|c|c|c|c|c|c|c|c|}
\hline \multicolumn{2}{|c|}{ Autocorrelation } & \multicolumn{3}{|c|}{ Partial Correlation } & \multirow{2}{*}{$\begin{array}{c}\mathrm{AC} \\
0.106\end{array}$} & \multirow{2}{*}{$\begin{array}{l}\text { PAC } \\
0.106\end{array}$} & \multirow{2}{*}{$\begin{array}{l}\text { Q-Stat } \\
0.2041\end{array}$} & \multirow{2}{*}{$\frac{\text { Prob }}{20.651}$} & \multicolumn{2}{|c|}{ Autocorrelation } & \multicolumn{3}{|c|}{ Partial Correlation } & \multicolumn{2}{|r|}{$\mathrm{AC}$} & PAC & \multirow{2}{*}{$\begin{array}{l}\text { Q-Stat } \\
0.0314\end{array}$} & \multirow{2}{*}{$\frac{\text { Prob }}{20.859}$} \\
\hline D & 1 & D & 1 & 1 & & & & & p & 1 & 1 & 巾 & 1 & 1 & 0.042 & 0.042 & & \\
\hline $\bar{b}$ & I & I & 1 & 2 & 0.067 & 0.056 & 0.2919 & 0.864 & $\square$ & 1 & 1 & $\square$ & 1 & 2 & 0.143 & 0.142 & 0.4353 & 0.804 \\
\hline b & I & I & 1 & 3 & 0.045 & 0.032 & 0.3341 & 0.953 & $\square$ & ' & 1 & 口 & 1 & 3 & 0.165 & 0.157 & & 0.798 \\
\hline D & $\mathrm{I}$ & b & 1 & 4 & 0.113 & 0.103 & 0.6290 & 0.960 & b & 1 & 1 & $b$ & 1 & 4 & 0.088 & 0.063 & 1.1938 & 0.879 \\
\hline d & 1 & ' & 1 & 5 & -0.099 & -0.127 & 0.8773 & 0.972 & i & I & I & d & 1 & 5 & -0.036 & -0.086 & 1.2263 & 0.942 \\
\hline $1 \square$ & 1 & $1 \square$ & 1 & 6 & -0.300 & -0.303 & 3.4269 & 0.754 & a & I & i & 미 & 1 & 6 & -0.1 & -0.159 & 1.5380 & 0.957 \\
\hline 10 & $\mathrm{I}$ & ב & 1 & 7 & 0.058 & 0.13 & & 0.83 & ב & I & I & a & 1 & & & & & 0.967 \\
\hline - & I & 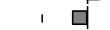 & 1 & 8 & -0.162 & -0.163 & 4.4852 & 0.811 & 口 & I & 1 & 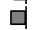 & 1 & 8 & -0.199 & -0.166 & 3.3048 & 0.914 \\
\hline & 1 & 1 & 1 & 9 & -0.070 & -0.00 & 4.692 & 0.86 & 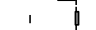 & 1 & 1 & b & 1 & 9 & 0.039 & 0.132 & & 0.948 \\
\hline , 口 & 1 & 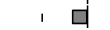 & 1 & 10 & -0.2 & -0.1 & 7.29 & 0.6 & $1 \square$ & I & 15 & $\square$ & 1 & 10 & & & & 0.419 \\
\hline 1 & 1 & $\overline{1}$ & 1 & 11 & -0.033 & -0.074 & 7.3663 & 0.769 & 10 & I & 1 & 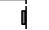 & 1 & 11 & -0.083 & -0.035 & 10.683 & 0.470 \\
\hline$\hat{0}$ & 1 & b & 1 & 12 & 0.03 & 0.04 & 7.48 & 0.8 & 1 & I & 1 & b & & 12 & & & & 0.556 \\
\hline d & I & I & 1 & 13 & -0.04 & -0.0 & 7.78 & 0.8 & a & 1 & 1 & i & 1 & 13 & & & 34 & 0.574 \\
\hline 1 & I & i & 1 & 14 & 0.013 & -0.056 & 7.8277 & 0.898 & 1 & I & 1 & $\emptyset$ & 1 & 14 & -0.003 & 0.040 & 11.436 & 0.651 \\
\hline
\end{tabular}

نموذج الصادرات الزراعية

Date: 10/18/18 Time:01:50 Sample: 20032018

Included observations: 15
Dato: 10/18/18 Time:01:50

$$
\text { نموذج الميزان التجارى الكلى }
$$

Sample: 20032018

Included observations: 15

\begin{tabular}{|c|c|c|c|c|c|c|c|c|c|c|c|c|c|c|c|c|c|}
\hline \multicolumn{2}{|c|}{ Autocorrelation } & \multicolumn{2}{|c|}{ Partial Correlation } & \multicolumn{2}{|r|}{$\mathrm{AC}$} & PAC & Q-Stat & Prob & \multicolumn{2}{|c|}{ Autocorrelation } & \multicolumn{2}{|c|}{ Partial Correlation } & \multicolumn{2}{|r|}{$A C$} & PAC & \multirow{2}{*}{$\begin{array}{l}\text { Q-Stat } \\
1.3430\end{array}$} & \multirow{2}{*}{ Prob } \\
\hline 4 & I & q & 1 & & -0.089 & -0.089 & 0.1436 & 0.705 & $1 \square$ & 1 & $1 \square$ & I & & -0.272 & -0.272 & & \\
\hline 15 & 1 & $\square$ & 1 & & -0.442 & -0.454 & 3.9822 & 0.137 & 1 & 1 & 1 & 1 & 2 & 0.031 & -0.046 & 1.3620 & 0.506 \\
\hline$b$ & I & 10 & I & 3 & 0.063 & -0.043 & 4.0669 & 0.254 & 0 & 1 & D & $\mathrm{I}$ & 3 & 0.130 & 0.137 & 1.7236 & 0.632 \\
\hline$\square$ & 1 & 4 & 1 & 4 & 0.134 & -0.081 & 4.4852 & 0.344 & d & 1 & 1 & 1 & 4. & -0.093 & -0.022 & 1.9250 & 0.750 \\
\hline$\square$ & I & $\square$ & 1 & 5 & 0.100 & 0.154 & 4.7402 & 0.448 & $\square$ & 1 & $\square$ & 1 & 5 & 0.189 & 0.171 & 2.8382 & 0.725 \\
\hline$i$ & 1 & $b$ & 1 & 6 & -0.031 & 0.047 & 4.7672 & 0.574 & 미 & ' & $1 \quad 4$ & I & & -0.134 & -0.065 & 3.3495 & 0.764 \\
\hline 미 & I & 미 & 1 & 7 & -0.203 & -0.110 & 6.0756 & 0.531 & , 口 & I & , 口 & ' & & -0.191 & -0.265 & 4.5063 & 0.720 \\
\hline 1 & 1 & 1 & 1 & 8 & 0.012 & -0.042 & 6.0807 & 0.638 & 口 & I & 17 & 1 & 8 & 0.166 & 0.007 & 5.5098 & 0.702 \\
\hline$i$ & I & 미 & I & 9 & 0.025 & -0.178 & 6.1080 & 0.729 & 미 & I & 1 & ' & 9. & -0.122 & -0.030 & 6.1398 & 0.726 \\
\hline d & I & d & 1 & 10 & -0.032 & -0.088 & 6.1607 & 0.802 & 미 & I & , 口 & ' & 10 & -0.143 & -0.191 & 7.1874 & 0.708 \\
\hline i & I & 미 & I & 11 & -0.031 & -0.115 & 6.2201 & 0.858 & d & 1 & 1 口 & 1 & 11. & -0.104 & -0.226 & 7.8799 & 0.724 \\
\hline 1 & I & i & ' & 12 & 0.009 & 0.005 & 6.2270 & 0.904 & i & 1 & 1 & 1 & 12 & 0.040 & 0.050 & 8.0130 & 0.784 \\
\hline 1 & I & i & 1 & 13 & -0.018 & -0.045 & 6.2661 & 0.936 & b & I & b & 1 & 13 & 0.057 & 0.068 & 8.4258 & 0.815 \\
\hline 1 & 1 & 1 & 1 & 14 & 0.001 & -0.004 & 6.2664 & 0.959 & प] & 1 & 1 & 1 & 14 & -0.054 & -0.006 & 9.1797 & 0.819 \\
\hline
\end{tabular}


جدول (5) اختبار العلاقة السببية Granger Causality Test بين سعر صرف الدولار ورصبد الميزان التجاري والميزان الزراعى (الصادرات

\begin{tabular}{|c|c|c|}
\hline Nuil Hypotheses & F-Statistics & Prop \\
\hline $\mathrm{D}\left(\mathrm{x}_{1}\right)$ does not Granger Cause $\mathrm{D}(\mathrm{y})$ & 2.4900 & 0.7848 \\
\hline $\mathrm{D}(\mathrm{y})$ does not Granger Cause $\mathrm{D}\left(\mathrm{x}_{1}\right)$ & 4.2223 & 0.0509 \\
\hline $\mathrm{D}\left(\mathbf{x}_{2}\right)$ does not Granger Cause $\mathrm{D}(\mathrm{y})$ & 1.0266 & 0.3966 \\
\hline $\mathrm{D}(\mathrm{y})$ does not Granger Cause $\mathrm{D}\left(\mathbf{x}_{2}\right)$ & 7.5463 & 0.0119 \\
\hline $\mathrm{D}\left(\mathbf{x}_{3}\right)$ does not Granger Cause $\mathrm{D}(\mathrm{y})$ & 1.8167 & 0.2174 \\
\hline $\mathrm{D}(\mathrm{y})$ does not Granger Cause $\mathrm{D}\left(\mathrm{x}_{3}\right)$ & 4.0246 & 0.0564 \\
\hline $\mathrm{D}\left(\mathrm{x}_{4}\right)$ does not Granger Cause $\mathrm{D}(\mathrm{y})$ & 0.4443 & 0.6546 \\
\hline $\mathrm{D}(\mathrm{y})$ does not Granger Cause $\mathrm{D}\left(\mathrm{x}_{4}\right)$ & 1.4348 & 0.2878 \\
\hline $\mathrm{D}\left(\mathrm{x}_{5}\right)$ does not Granger Cause $\mathrm{D}(\mathrm{y})$ & 0.0419 & 0.9591 \\
\hline $\mathrm{D}(\mathrm{y})$ does not Granger Cause $\mathrm{D}(\mathbf{x} 5)$ & 0.8550 & 0.4571 \\
\hline $\mathrm{D}\left(\mathrm{x}_{6}\right)$ does not Granger Cause $\mathrm{D}(\mathrm{y})$ & 0.0196 & 0.9806 \\
\hline $\mathrm{D}(\mathrm{y})$ does not Granger Cause $\mathrm{D}\left(\mathrm{x}_{6}\right)$ & 1.9451 & 0.1986 \\
\hline
\end{tabular}

المصدر: جمعت وحسبت باستخدام برنامج (E- Views) من بيانات جدول (1)

ويشير معدل التغير لسعر الصرف أنه إذا ارتفع سعر صرف الدولار بنسبة 10\% فسوف يؤدى ذلك إلى ارتفاع الصادرات بنسبة تمثل نحو

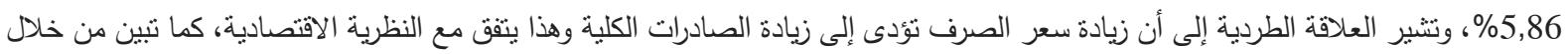

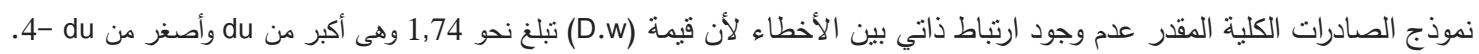
ب- التفسير الإحصائي لنتائج نموذج الواردات الكلية: يتضح من نتائج تقدير نموذج الواردات الكلية تأثثر سعر الصرف على الواردات الكلية خلال الفترة (2003-2018) حيث بلغ معامل الارتباط حوالى 0,914 مما يثبر إلى وجود علاقة عكسية بين الواردات الكلية (متغير مستقل) وسعر الصرف (متغير نابع)، كما بلغ معامل التحديد المعدل

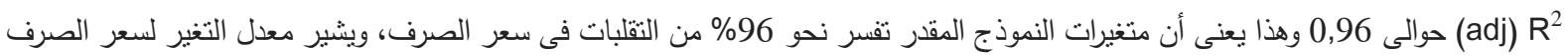

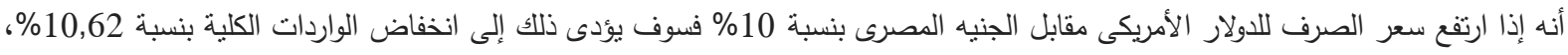
وبالتالى زيادة رصيد المبزان التجاري وهذا يتفق مع النظرية الاقتصادية، ويتضح من نموذج الواردات الكلية عدم وجود ارتباط ذاتي بين الإخطاء لأن

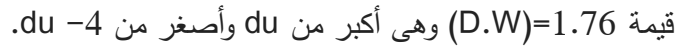

$\log (\dot{Y})=14.563-1.062 \log \left(X_{2}\right)+0.8654 A_{(1)}$
$(0.89) *$
$(-3.86)^{* * *}$
$(29.21)^{*}$

$\mathrm{R} 2=0.91 \quad \mathrm{~F}=272.6 \quad \mathrm{D} . \mathrm{W}=1.72$

ج- التفسير الإحصائي لنتائج نموذج الميزان التجارى: يفسر نموذج الميزان التجارى تأثير سعر الصرف على رصيد الميزان التجارى خلاد الفترة (2003-2018)، حيث تبين أن معامل الارتباط بلغ

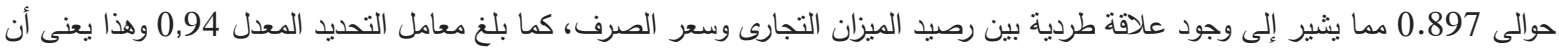
متغيرات النموذج تفسر حوالى 94\% من التقلبات فى سعر الصرف بينما باقي النسبة ترجع إلى عوامل أخرى. $\log \left(\dot{Y}_{1}\right)=14.869-1.062 \log \left(\mathrm{X}_{3}\right)+0.8695 \mathrm{AR}_{(1)}$

$$
(0.86)^{* *}(-3.95)^{* * *}(26.60) *
$$

$R^{2}=0.941 \quad F=59.6 \quad$ D.W $=1.76$

وتتبر العلاقة الطردية إلى أن زيادة سعر الصرف يؤدى ذلك إلى رصيد الميزان التجارى وهذا يتوافق مع النظرية الاقتصادية، ويتضح من

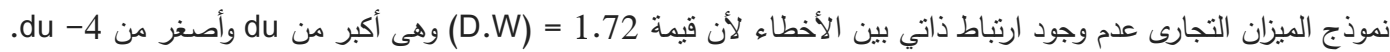

د - التفسير الإحصائي لنتائج نموذج الصادرات الزراعية: يتضح من نتائج تقدير نموذج الصادرات الزراعية تأثير سعر الصرف على الصادرات الزراعية خلاد الفترة (2003-2018) حيث بلغ معامل الارتباط حوالى 0,89 مما يشير إلى وجود علاقة طردية بين الصادرات الزراعية (متغير مستقل) وسعر الصرف (متغير تابع)، كما بلغ

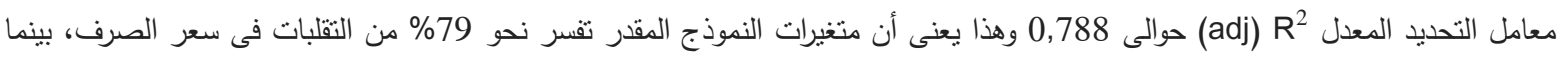
النسبة الباقية من التقلبات ترجع إلى عوامل آخري لم يتضمنها النموذج، ويشير معدل التغير لسعر الصرف أنه إذا ارتفع سعر الصرف للاولار

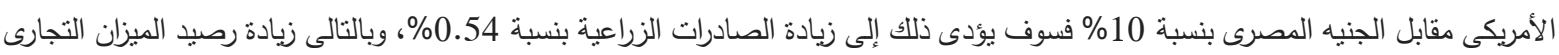


وهذا يتفق مع النظرية الاقتصادية، ويتضح من نموذج الصادرات الزراعبة عدم وجود ارتباط ذاتي بين الإخطاء لأن قيمة D.W)=1.96 وهى أكبر من du وأصغر من du

$\log (\dot{Y})=1.965+0.054 \log \left(\mathrm{X}_{4}\right)+0.896 \mathrm{AR}_{(1)}$
$(0.59)$
$(1.56)^{* * *}$
$(10.85)^{*}$

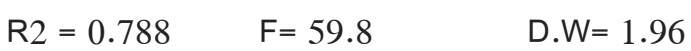

هـ - التفسير الإحصائي لنموذج تقدير الواردات الزراعية:

يتضح من نتائج تقدير نموذج الواردات الزراعية تأثير سعر الصرف على الواردات الزير لزاردية خلال الفترة (2003-2018) حيث بلغ

معامل الارتباط حوالى 0,934 مما يشير إلى وجود علاقة عكسية بين الواردات الزراعية (متغير مستقل) وسعر الصرف (متغير تابع)، كما بلغ

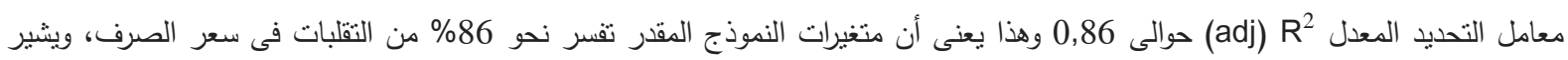
معدل التغير لسعر الصرف أنه إذا ارتفع سعر الصرف للاولار الأمريكى مقابل الجنيه المصرى بنسبة 10\% فسوف بؤئ بؤدى ذلك إلى انخفاض الواردات

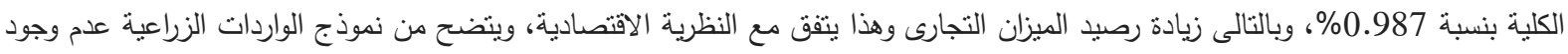

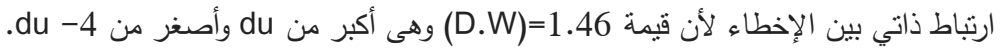

$\log \left(Y^{\prime}\right)=314.563-0.987 \log \left(X_{5}\right)+0.4654 A R{ }_{(1)}$
$(0.89) *$
$(-3.86)^{* * *}$
$(29.21)^{*}$

$\mathrm{R} 2=0.86 \quad \mathrm{~F}=212.6 \quad \mathrm{D} . \mathrm{W}=1.46$

و - التفسير الإحصائي لنموذج تقدير الميزان الزراعى:

يتضح من نتائج تقدير نموذج الميزان الزراعى تأثير سعر الصرف على رصيد الميزيز الميزان الزراعى خلال الفترة (2003-2018) حيث بلغ

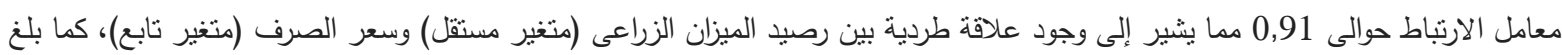

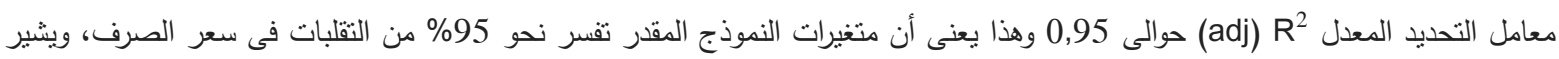

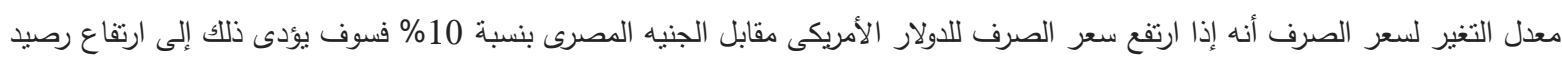

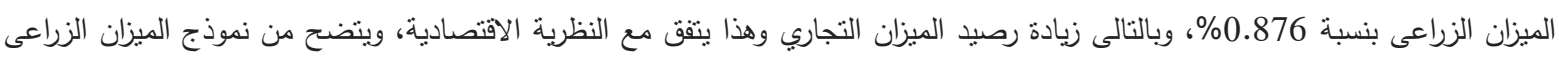

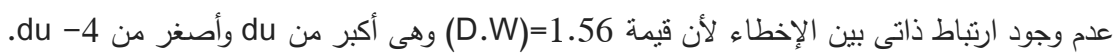
$\log \left(Y^{\prime}\right)=514.563-0.876 \log \left(X_{6}\right)+0.2654$ AR ${ }_{(1)}$

$$
\begin{array}{lll}
(0.89) \quad(-3.86) \quad(29.21)
\end{array}
$$

$\mathrm{R} 2=0.95 \quad \mathrm{~F}=85.7 \quad \mathrm{D} . \mathrm{W}=1.56$

4- اختبار استقراريه سلسلة البواقي للنماذج المقدرة :

يعد اختبار استقراريه سلسلة البواقي لنماذج التجارة الكلية والزراعية هام بعد إتمام تقدير النماذج والتفسير الإحصائي ويسمى باختبار ديكي فولر

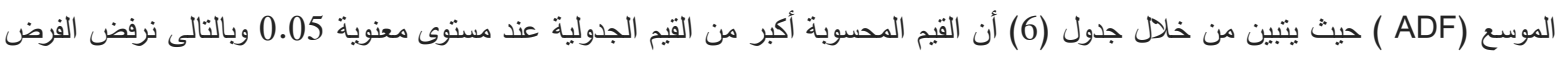
العدميأي عدم وجود جزر الوحدة ونقبل الفرض البديل أي أن سلسلة البواقى مستقرة من الدرجة صفر ، وبالتالى نوجد علاقة تكاملية مشتركة بين سعر الصرف للدولار ونماذج التجارة الخارجية الكلية والزراعية.

جدول (6) نتائج اختبار (ADF) لبواقي النماذج المقدرة خلا الفترة (2003-2018)

\begin{tabular}{|c|c|}
\hline اختبار جزر الوحدة T-statistic (Unit Root Test) & 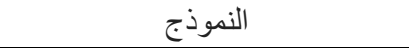 \\
\hline $3.48-$ & 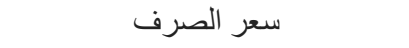 \\
\hline $2.39-$ & بو اقى نموذج الصادر ات الكلية \\
\hline 2.39- & بواقى نموذج الواردات الكلية \\
\hline $2.61-$ & بو اقى نموذج الميز ان التجارى الكلى \\
\hline $4.44-$ & بو اقى نموذج الصـادر ات الزر اعية \\
\hline $3.86-$ & بو اقى نموذج الواردات الزر اعية \\
\hline $4.64-$ & بو اقى نموذج الميزان الزر اعى الكلى \\
\hline
\end{tabular}

المصدر : جمعت وحسبت من نتائج نموذج لباستخدام برنامج (EARs 9-Views) 
ونستنتج من دراسة التقدير القياسى لنموذج أثز تغير سعر الصرف على الميزان التجارى والميزان الزراعى خلال الفترة(2003-2018) من خلا التقدير القياسى لطريقة التكامل المتزامن لاختبار وجود العلاقة السبيبة طويلة المدى بين سعر صرف الجنيه المصرى مقابل الدولار الأمريكي ورصيد

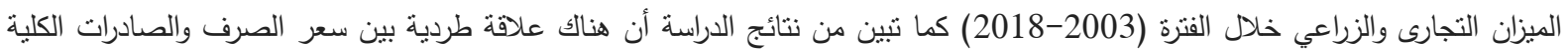
والزراعية، بينما كانت العلاقة عكسية بين سعر الصرف والواردات الكلية والزراعية فى حين كانت العلاقة طردية بين سعر الصرف والميزان التجارى

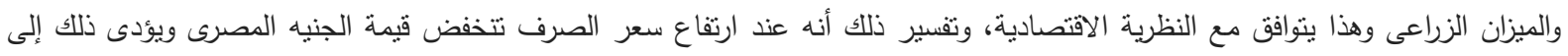
انخفاض تكاليف عناصر الإنتاج المحلية بالنسبة للعالم الخارجي مما يؤدى إلى انخفاض الأسعار المحلية مقارنة بالأسعار العالمية ويترتب على ذللك

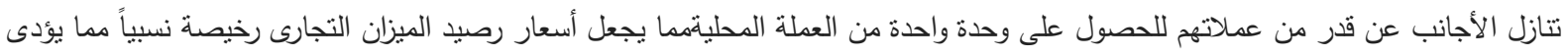
إلى زيادة الصادرات وتراجع الواردات وبالتالي زيادة رصيد الميزان التجارى الزراعى.

تعتبر التغيرات التي طرأت على سعر الصرف للجنيه المصرى مقابل الدولار الأمريكي ذات اثر فعال وكبير على حركة التجارة الخارجية المصرية وخاصة التجارة الخارجية الزراعية مما شكل مشكلة اقتصادية واجبة الدراسة وبذلك فقد تتاول البحث قياس أثز تلك التغيرات الحادثة من فن خلا قياس كفاءة التجارة الخارجية الكلية والزراعية (صادرات، واردات) خلال الفترة (2003-2018) ، فقد تنين من خلال البحث أن معدل التغير

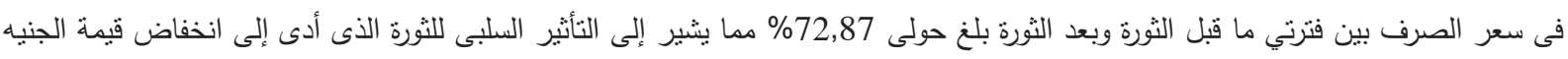

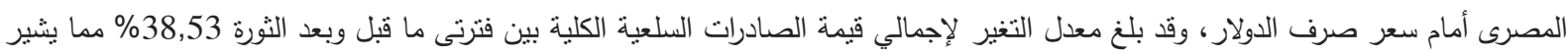

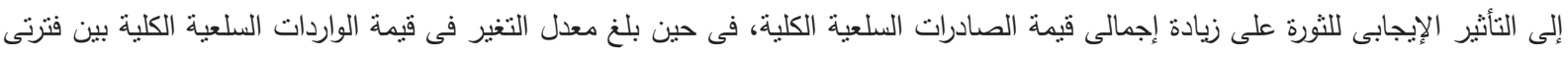

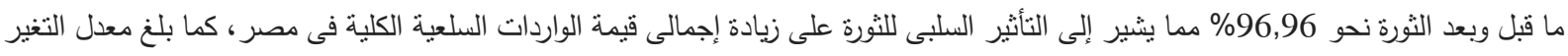

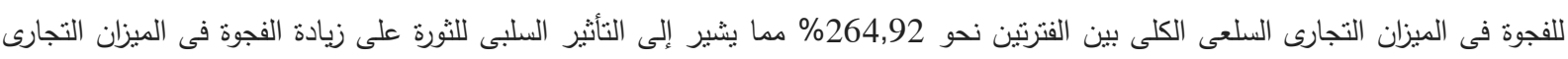

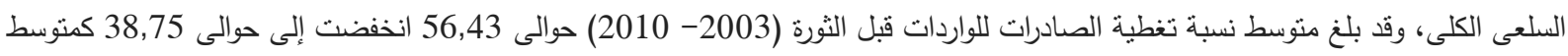
للفترة بعد الثورة (2011 - 2018)، وقد بلغ معدل التغير لقيمة الصادرات من السلع الزراعية بين فترتى ما قبل وبعد الثورة نحو

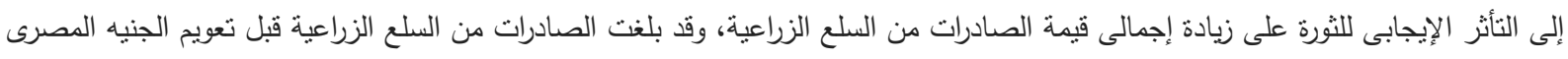

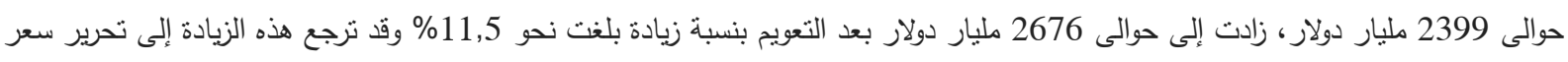

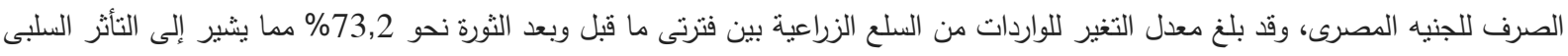

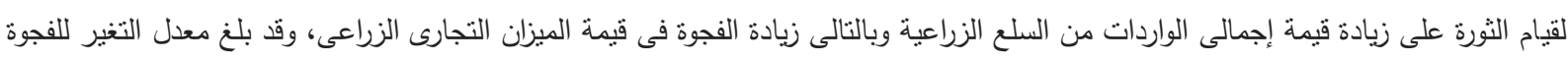

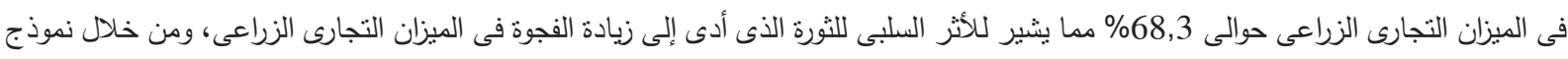

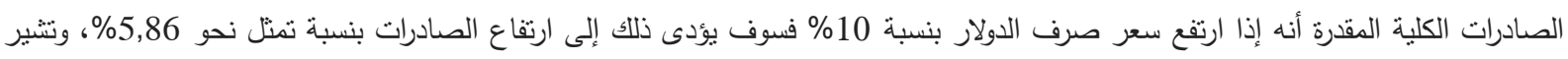

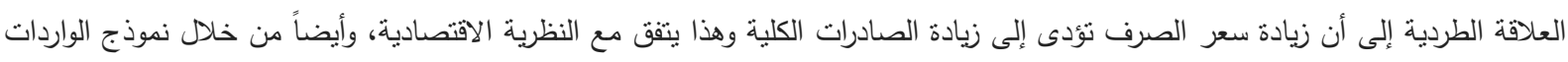

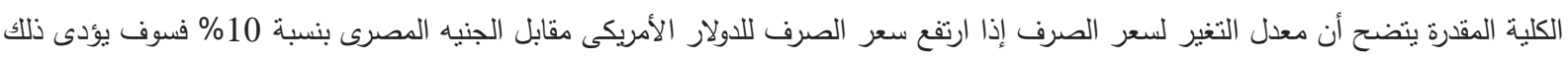

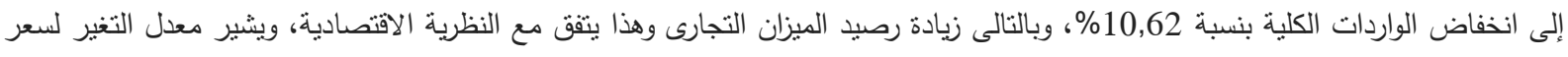

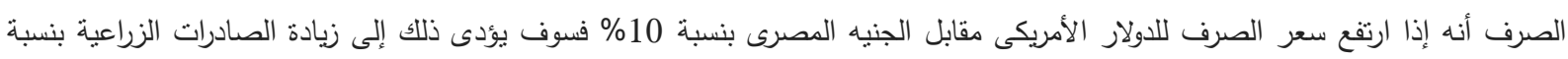

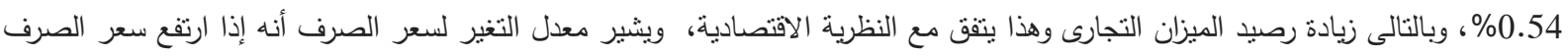

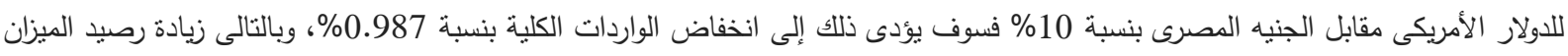
التجارى، ويثير معدل التغير لسعر الصرف أنه إذا ارتفع سعر الصرف للاولار الأمريكى مقابل الجنيه المصرى بنسبة 10\% فسوف يؤدى ذلك إلى إلى ارتفاع رصيد الميزان الزراعى بنسبة 0.876\%، وبالتالى زيادة رصيد الميزان التجارى.

وقد أوضحت النتائج المتحصل علئها من خلال نموذج تقدير أثز سعر الصرف على متغيرات البحث وجود علاقة طردية بين كل من سعر الصرف كمتغير تابع والصادرات الكلية ورصيد الميزان التجارى الكلى والصادرات الزراعية ورصيد الميزان التجارى الزراعى كلاً على حدة كمتغيرات

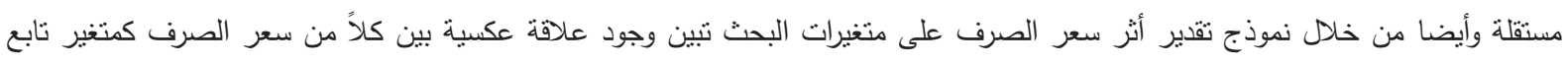

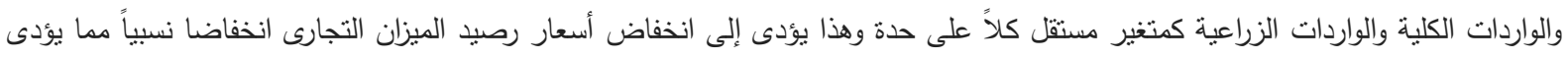

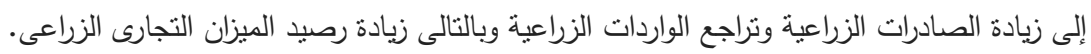


- العمل على تشجيع المنتجين والمستثمرين بالقطاع الزراعى على زيادة الإنتاج للمحاصيل التي يتم استيرادها بالعملات الأجنبية لنقليص الفجوة بين

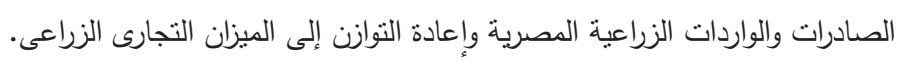

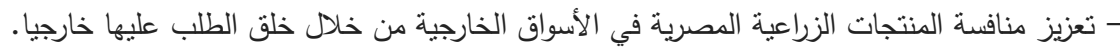

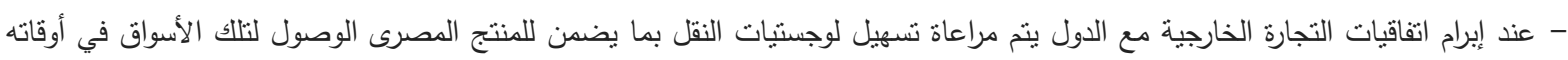
المحددة حتى لا يفقد تتافسيته بين منتجات الدول الأخرى. - ضرورة التوسع فى إنتاج أهم السلع الغذائية، لوجود ارتباط بين سعر الصرف وأسعار أهم السلع الأساسية الغذائية وخاصة أن مصر تشتورد السلع الغذائية الأساسية، بالإضافة إلى ترشيد الاستهلالك من أهم تلك السلع الغذائية. - العمل على ربط العملة المحلية بسلة عملات أجنيبه والتخلص من التبعية الاقتصادية لعملة واحدة وهى الدولار .

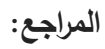

www.cbe.org.eg الموقع الإلكترونى للبنك المركزى المصري-

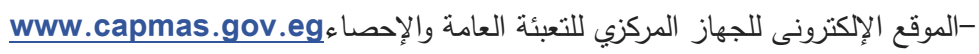

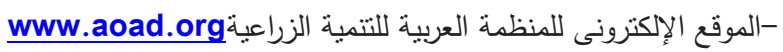

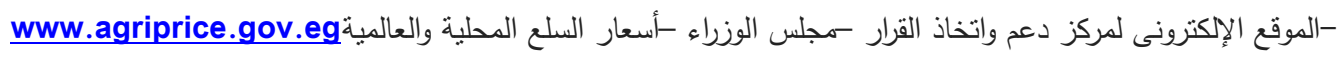
- الموقع الإلكترونى لوزارة الاستثمار - www.gafi.gov.eg - البنك المركزى المصرى، النشرة الإحصائية الثهرية، أعداد متفرقة.

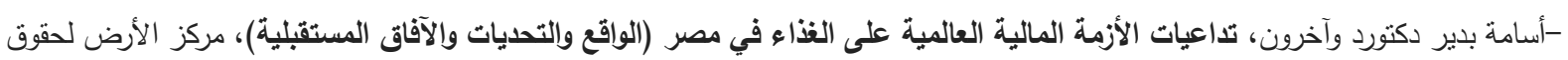

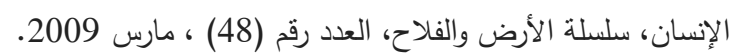

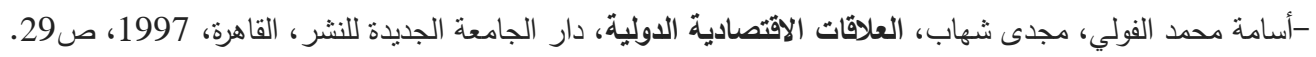

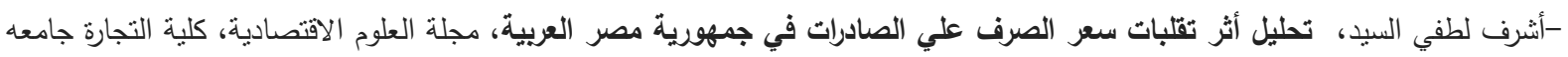
طنطا، 2012. - أمنية حلمى -تأثير انخفاض سعر الصرف على الميزان التجاري المصرى، المركز المصري للاراسات الاقتصادية، 2012.

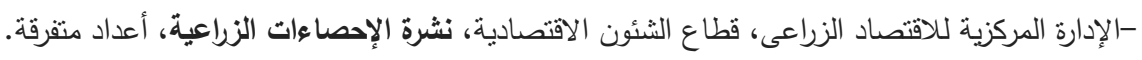

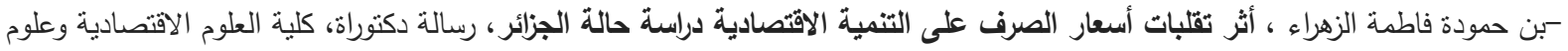

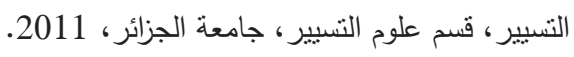

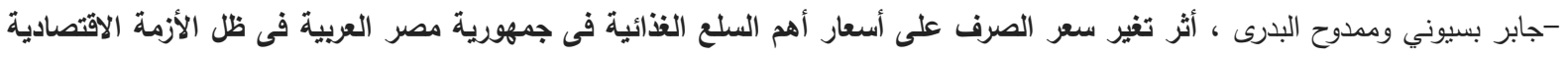

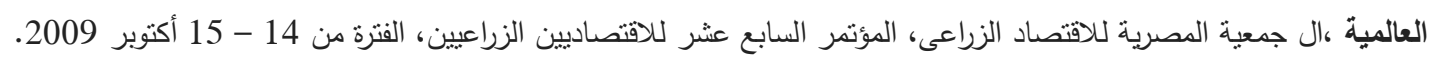

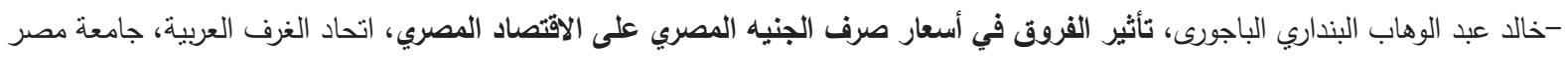
لللعلوم والنكنولوجيا، 2016. - ممدوح البدرى محمد، "أثثر تغير سعر الصرف على التجارة الخارجية الكلية والززاعية فى مصر"، مجلة المنوفية للاقتصاد الزراعى والعلوم الاجتماعية، أكثوبر 2017.

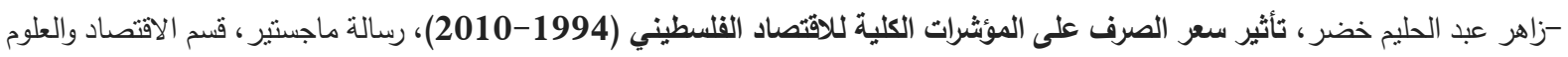

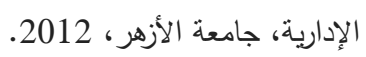
-سامية عمار ، تأثير سعر الأرثر، الصرف على الناتج المحلي الإجمالي في الاقتصاد المصري، مجلة النهضة، كلية الاقتصاد والعلوم السياسية، جامعة القاهرة، العدد السادس عشر، يوليو 2003. -سعيد على عبد العزيز ، محمد فوزي أبو السعود، العلاقة بين سعر الصرف الحقيقي والناتج الحقيقي في مصر دراسة تحليلية قياسية ، مجلة الحقوق للبحوث القانونية والاقتصادية، 2002.

الكلمات المفتاحية:سعر الصرف- التجارة الخارجية- الميزان التجاري- النجارة الدولية- الدين العام- الناتج المحلي- الاقتصاد المصري- القطاع الزراعي 


\title{
The Impact of Exchange Rate liberalization On Foreign Trade in the Egyptian Agricultural Sector
}

\author{
Dr. El sayed Abd Elazim Elsayed Elkhishin \\ Higher Institute for Agricultural \\ Co-operation
}

\author{
Dr. Zaky Ismail Zaki Nassar \\ Desert Research Center
}

\section{Corresponding Author: elkhishinss@gamil.com}

\begin{abstract}
Summary:
Exchange rate developments have a significant impact on the Egyptian foreign trade; especially in the agricultural sector, in a way that required assessment and investigation. In this research, we attempt to measure the impact of recent exchange rate developments through measuring the efficiency of total foreign trade and agricultural trade (imports and exports) during the period (2003-2018). Our results indicate that exchange rate changed by around $72.87 \%$ following the revolution in 2011. This indicates a devaluation in the Egyptian national currency as a result of the revolution. However, this devaluation had a positive impact on the Egyptian commodity exportsthat increased by around $38.53 \%$ Indicating the positive impact of the revolution. On the other hand, the total value of imports increased by around $96.96 \%$ during the same period which indicates a strong negative impact of the devaluation on imports. These changes reveal the widening the gap in the trade balance during the mentioned period. The gap widened by around $264.92 \%$. Exports coverage to imports changes by around 56.43 during the period (2003-2010) then to $38.75 \%$ during the period $2011-2018$.

Total exports of agricultural products changed by around $41.3 \%$ which reveals a positive impact of the revolution on the agricultural exports. Pre-devalutaion total exports amounted around 2399 billion dollars and increased to around 2676 billion dollars; with a total increase of $11.5 \%$. This increase is a result of the devaluation. Total agricultural imports changed by around $73.2 \%$, indicating the negative impact of the revolution on the increase of the total value Imports of agricultural commodities and thus increase the gap in the agricultural trade balance.The agricultural trade balance gap increased by around $68.3 \%$ which reveals the negative impact of the revolution. According to the estimated aggregate agricultural exports model, an increase in exchange rate by $10 \%$ leads to an increase in total exports by around $5.86 \%$. the positive relation between exchange rate devaluation and total exports is consistent with economic theory. Our estimated imports model shows that if exchange rate changes by $10 \%$ this leads to a decrease in total Egyptian imports by around $10.62 \%$, thus increasing the balance of trade balance. This is also consistent with the economic theory. The rate of change in the exchange rate indicates that if the exchange rate of the US dollar against the Egyptian pound increases by $10 \%$, this will increase the agricultural exports by 0.54 which is also consistent with economic theory. The rate of change in the exchange rate indicates that if the exchange rate of the US dollar against the Egyptian pound increases by $10 \%$, this will lead to a decrease in total imports by $0.987 \%$, thus increasing the balance of the trade balance. Finally, If the exchange rate of the US dollar against the Egyptian pound increases by $10 \%$, the balance of agricultural balance will rise by $0.876 \%$, thus increasing the balance of trade balance.

Our model revealed a positive relationship between the exchange rate as a dependent variable, total exports, balance of trade balance, agricultural exports and balance of agricultural trade balance separately as independent variables.Results also reveal an inverse relationship between exchange rate as a dependent variable and total imports and agricultural imports as independent variables. This leads to a relative decrease in trade balance and hence an increase in agricultural exports and in the agricultural trade balance.
\end{abstract}

\section{Recommendations}

- Encouraging producers and investors in the agricultural sector to increase the production of imported products in order to decrease the trade gap and retain the balance in the agricultural trade balance.

- Increase the competitiveness of the Egyptian agricultural exports in foreign markets and create demand on them.

- Improve transportation logistics as part of trade agreements in order to increase the outreach of the Egyptian products in time so that they won't lose their competitiveness.

- Widen the production of key strategic products since there is a high correlation between exchange rate and the price of these goods; this is given that Egypt is an importer of such goods. Rationalizing the consumption of these products is also a necessity.

- $\quad$ Linking the national currency with a basket of foreign commodities to decrease the dependency on U.S dollars. 